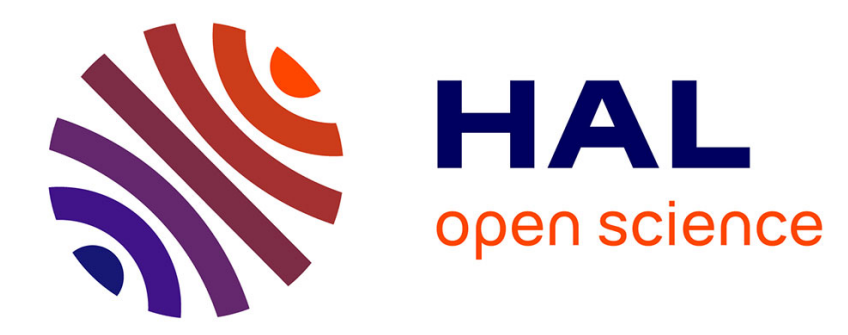

\title{
LA MICROFLORE MAMMAIRE EN RAPPORT AVEC LA TRAITE
}

Constantino Gorini

\section{To cite this version:}

Constantino Gorini. LA MICROFLORE MAMMAIRE EN RAPPORT AVEC LA TRAITE. Le Lait, 1924, 4 (40), pp.856-859. hal-00894791

\section{HAL Id: hal-00894791 \\ https://hal.science/hal-00894791}

Submitted on 1 Jan 1924

HAL is a multi-disciplinary open access archive for the deposit and dissemination of scientific research documents, whether they are published or not. The documents may come from teaching and research institutions in France or abroad, or from public or private research centers.
L'archive ouverte pluridisciplinaire $\mathbf{H A L}$, est destinée au dépôt et à la diffusion de documents scientifiques de niveau recherche, publiés ou non, émanant des établissements d'enseignement et de recherche français ou étrangers, des laboratoires publics ou privés. 


\title{
LA MIGROFLORE MAMMIIRE EN RAPPORT AVEG LA TRAITE,
}

\author{
par le Professeur Constantino GORINI,
}

Directeur du Laboratoire de Bactériologie à l'Ecole Royale Supérieure d'Agriculture de Milan.

Il y a vingt trois ans que j'ai démontré que la microflore communément habituelle de la mamelle des vaches saines est constituée de coccus producteurs d'acide et de présure (cocci acidopresamigeni). D'après ma théorie acidoprotéolytique de la maturation du fromage, j'ai attribué à ceux-ci une influence propice dans ce processus parce que avec leurs enzymes ils peptonisent la caséine en milieu acide.

En effet, ces coccus, dont j'ai décrit plusieurs types $[2$, , se retrouvent dans la généralité des fromages.

On a objecté à cette idée que les coceus disparaissent assez vite de la pâte de certains fromages; mais j'ai fait remarquer que, même dans ce cas, laction de leur's enzymes persiste et continue même après leur mort. Du reste la galactase, cet enzyme soi disant naturel du lait, auquel on attribue un rôle maturatif n'est autre chose que l'enzyme caséolytique de ces coccus. La coopération de ces germes dans la maturation des fromages peut done être admise généralement. Voilà pour ce qui concerne la microflore mammaire qui existe dans des conditions normales.

Pourtant, dans des travaux successifs (à partir de 1906 [3]), j'ai signalé plusieurs cas dans lesquels cette microflore mammaire doit être considérée comme anormale. Naturellement je fais abstraction des cas de maladie et d'inflammation manifeste de la mamelle. Nous entrons ici dans le domaine pathologique où l'on parle de mammites dans lesquelles la sécrétion lactée est profondément altérée par l'action des germes pyogènes. La particularité de mes observations réside dans le décèlement que la microflore mammaire peut aussi être anormale sans qu'on remarque aucune inflammation de l'organe ni altération du lait. Ce fait a été non-seulement confirmé,mais amplifié par divers auteurs, notamment américains et suisses. Parmi les ouvrages suisses, il faut citer plus spécialement les travaux publiés par le Laboratoire de Bactériologie de Liebefeld, près de Berne [4], où j'ai fait, en 1901, mes premières recherches au sujet de la microftore mammaire et où mes inductions au sujet de leur importance fromagère y avaient été accueillies avec incrédulité par le Directeur feu Dr Freudenreich, incrédulité qui pendant quelque temps fut également partagée par d'autres collègues Aujourd'hui au contraire, il est établi que les vaches dont tous les quartiers de la 
mamelle ont une microflore normale, sont rares. Au moins un des quartiers a, même d'une façon persistante, une microflore anormale sans qu'aucun indice ne puisse le distinguer des autres, ni que son lait ait un aspect anormal.

L’anormalité de la microflore mammaire peut être représentée,soit par une quantité exceptionnelle, soit par une exaltation fonctionnelle des germes habituels. Aussi bien, dans un cas comme dans l'autre, le danger pour la fromagerie provient tant de l'action directe de la microflore mammaire sur le lait que des phénomènes d'irritation dans les tissus glandulaires qui ont une répereussion sur les qualités du lait. Aujourd'hui, il y a une tendance à admettre que si la microflore mammaire, dans les conditions ordinaires,ne détermine pas d'irritation dans. la mamelle, il faut en attribuer la cause à l'équilibre qui s'établit entre l'action des bactéries et la réaction cellulaire. Au contraire les anormalités de la microflore mammaire déterminent des phénomènes de réaction lesquels, s'ils n'amènent pas toujours une réaction inflammatoire marquée, provoquent cependant une altération, une déviation de la fonction de celle-ci. De l'ensemble de toutes ces conditions anormales, il en résulte que le lait, tout en paraissant encore normal, soit. par ses caractères organoleptiques, soit par le contrôle chimique courant, est modifié soit dans sa constitution enzymaticochimique, soit dans sa taçon de se comporter vis-à-vis de la présure, soit enfin. dans ses propriétés microbicide et fermentative.

Or, on a à se demander pour quelle cause la microflore mammaire peut devenir anormale?

J'ai démontré qu'il suffit des stagnations du lait qui se constatent dans la mamelle par suite d'un refroidissement, de troubles digestifs, etc., mais le plus souvent par suite d'une traite imparfaite ou maladroite. Il est à remarquer que ces stagnations peusent être transitoires et. passer inapercues et néanmoins influencer tout autant surles qualités. enzymatiques du lait à tel point que celui-ci devient sujet aux phénomènes de la coagulation prématurée ou de la dissolution précoce comme on peut l'observer dans les essais zymoscopiques.

J'ai parlé d'une traite imparfaite et maladroite et je m'explique. Par traite impurfaite, j'entends celle dans laquelle le lait n'est pas complètement extrait à cause d'un égouttage final insuffisant. Par traite maladroite, j'entends celle dans laquelle le lait est retenu par la vache à cause de mauvaises manipulations effectuées par les trayeurs. Il est un fait acquis que même les palpations préparatoires parlesquelles le trayeur cherche à provoquer la sécrétion du lait déterminent plutôt nne rétention du lait si elles sont exécutées d'une manière brutale. Une traite imparfaite ou maladroite est surtout défavorable à la fromagerie lorsqu'on trait des vaches qui sont avares de leur lait ou qui ont. 
- des mamelles particulièrement sensibles aux engorgements du lait, ou bien pendant la période d'essuyage des vaches.

Par conséquent pour prévenir une microflore mammaire anormale, il faut une traite exécutée à fond et correcte, soigneuse.

La microflore mammaire peut aussi devenir anormale du fait de germes étrangers qui pénètrent à travers les trayons. Cette anormalité peut être apportée soit par la litière et les excréments sur lesquels reposent les tétines pendant le décubitus dela vache, soit surtout par les trayeurs qui se lubréfient les mains avec les premières goutelettes de lait pour masser la mamelle. On comprend que de cette façon les souillures de la main et de la mamelle externe peuvent passer et entrer facilement dans les voies lactiferes. La propreté des mains et de la mamelle, c'est-à-dire une traite propre (sinon rigoureusement aseptique), est donc nécessaire non-seulement pour ne pas enrichir de germes le lait qui est trait, $\mathrm{m}$ xis aussi pour ne pas infecter la microflore mammaire. Parmi les germes infectants les plus redoutables pour sa fromagerie sont le $B$. Coli et le $B$. Lactis aerogenes qui provoquent le boursouflement des fromages.

Mais ce n'est pas ma tâche de m'occuper de ces germes étrangers qui heureusement ne sont pas aptes à demeurer longtemps dans les mamelles ainsi que plusieurs autres espèces qui peuvent se rencontrer dans les trayons et dans les voies lactifères inférieures, et qui ne sont point à confondre avec la véritable microflore mammaire. Celle-ci demeure en permanence dans le tissu glandulaire même et elle se retrouve dans le lait même après la dispersion des premiers jets ; de sorte qu'il faut renoncer à obtenir du lait absolument amicrobien malgré toutes les précautions de la traite aseptique.

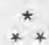

Or, j'ai la conviction basée sur une expérience assez prolongée, que les causes occultes de beaucoup d'insuccès dans la fabrication des fromages sont à rechercher dans la mieroflore mammaire habituelle, qui, si dans les conditions normales, doit être considérée comme étant utile, peut devenir dangereuse pour la fromagerie dans les conditions anormales créées par des défauts de la traite, alors mème que l'on aperçoit rien d'anormal dans l'état de l'organe et du lait au contrôle physique et chimique courant. Les essais du lait au zymoscope et à la présure peuvent, à côté de l'examen microscopique et bactériologique, rendre des bons services pour décéler ces conditions anormales. 


\section{BIBLIOGRAPHIE.}

1] Gorini. C.- Rend. R. Ist. Lomb. Sc. e Lett., 1901, 34%; Landw. Jahrb. d. Schweiz, 1902, p. 22 ; Revue générale dı Lait, 1902, I, p. 169 ; Centralbl. f. Bakter, II, Abt., 1902, 8, p. 139 ; Milchw. Zentralblatt, 1905, I, p. 49's.

2] Gorixi, G.-Rend. R, Acc. Lincei. 1902, XI, p. 159.

3] Gonini, C. - Rend. R. Ist. Lomb Sc. e Lett, 1906, 39० ; 1907, 400; 1914 , $47^{\circ} ; 1916,49^{\circ}$ : La Clinica Veterinaria, 1906, 290;1914, 38० ; Revue générale du Lait, $1907,6^{\circ}$, p. 179 et p. 553; Comptes Rendus du VIe Congrès International de Laiterte, Berne, 1914.

4] Burri, R.-Landw. Jahrb.d. Schaveiz, 1917, 30, p. 315.

Steck, W. - Schweiz. Zentralbl. f. Milchw., 1920, $\mathrm{n}^{0 \mathrm{~s}} 38-39$; Landw. Jahrb. d. Schweiz, 1921.

Koestuer, G. - Schweiz. Zentralbl. f. Milchw., 1921, no 5 et suivants ; Landw. Jarhb. d. Scliweiz, 1921 et 1922.

\section{BIBLIOGRAPHIE ANALYTIQUE.}

\section{$1^{\circ}$ LIVRES.}

\section{R. Guyot-Sionnest. - De la situation laitière dans la région IYonnaise, et de l'approvisionnement en lait de la ville de Lyon. Thèse soutenue devant MM. Ies Délégués de la Soeiété des Agriculteurs de France (Angers, juin 1924).}

Les élèves sortant de l'Ecole d'Agriculture rattachée à la Faculté Cathólique d'Angers doivent rédiger, sous la forme d'une thèse, le développement d'une question de leur choix. Tous ces travaux ne sont pas d'égalevaleur, mais il en est - et c'est le cas de la thèse de G.-S. - qui sont d'un très grand intérêt.

G.-S. a repris l'étude que j'avais faite en 1914 sur l'approvisionnement de Lyon en lait, avec la collaboration de MV. Birbis et MoreL, mais il l'a singu. Ièrement étendue. Depuis 1914, il y a eu. hélas! la guerre, avec toutes ses conséquences, avec tous ses iroubles, et dans la question soulevée par G.-S. ceux-ci el celle-là sont, économiquement, fort importants.

Le travail de G.-S. est d'une grande richesse de documentation ; c'est une bęsogne de première main, puisée à bonne source, et fruit d'une expérience personntlle, puisque G.-S. était le Secrétaire de la Section Laitière de l'Union des Syndicats Agricoles du Sud-Est, si importante, car elle groupe 130.000 adhérents.

Il es idées directrices qui ont guidé G.-S. dans sa thèse sont les trois suivantes :

$1^{\circ}$ Montrer que les conditions de la vente du lait en nature sont éminemment soumises à l'état de la consommation urbaine ;

'2o Montrer que les agriculteurs sont obligés de se soumettre à l'état du marché de la ville pour régler leur production laitière; 